\title{
CONSUMER PERCEPTIONS OF ONLINE SHOPPING
}

\section{Chuleeporn Changchit, Texas A\&M University - Corpus Christi chuleeporn.changchit@tamucc.edu}

\begin{abstract}
Many brick and mortar companies have decided to enter e-commerce markets. However, the effects of ecommerce on individual business are varied based on several conditions. The ability to attract and retain customers is important to the success of online businesses. This study examines how consumers perceive online shopping and which factors are perceived differently between consumers who prefer online shopping and consumers who prefer offline (physical store) shopping. The better an online business understands the perceptions of these shoppers, the higher the chance that they can attract and retain customers.
\end{abstract}

Keywords: Online Shopping, Internet Shopping, Consumer Perceptions, Electronic Commerce

\section{INTRODUCTION}

Increasing numbers of people are gravitating towards more intensive use of the Internet as the accessibility of technology, the availability of information, and the ability to interact through the Internet increase and evolve. Obvious capabilities of the Internet include avenues for gathering information, purchasing a product, or rendering a service. These advances in Internet technology allow for the expansion of shopping options beyond traditional methods that may be more time consuming. Issues with having to physically gather information with offline shopping methods are alleviated, and customers are better able to efficiently use their time. For instance, instead of having to physically visit different stores to compare prices or rely on circular pamphlets in newspapers, a consumer is able to search and retrieve needed information through the Internet.

The Internet explosion has opened the doors to a new electronic world. Consumers are now able to use the Internet for a variety of purposes such as research, communication, online banking, and even shopping. With such advantages, the Internet is rapidly becoming the main method of communication and of conducting business conveniently. With a growing number of households turning towards the Internet and the world of e-commerce to shop, invest, make payments, and do online banking, new technological advancements will have to come about to make these transactions secure.

However, not all consumers are participating in online transactions as part of the Internet boom. As more and more businesses continue to establish an online presence, they are finding that some consumers are still reluctant to shift in that same direction. For various consumers there are still concerns with security and passing personal data over the Internet. There is a disparity between the number of consumers who visit a site and the number of actual purchases being made. Despite the millions of people who use the Internet everyday and visit various shopping sites, the number of consumers who do not abandon their shopping carts but actually complete a purchase averages to only about three percent [25]. This leaves a large portion of the Internet population as non-participants in online transactions as compared to those who fully complete transactions online and make purchases. Instead, these non-participants may abandon the purchase completely or fulfill the transaction in an offline setting. As such, it is important for online businesses or offline businesses interested in venturing into the online market to understand their consumers' perceptions, online and offline, and what factors influence their shopping decisions. With better understanding of what factors play into consumer decision making in making transactions online or offline, retailers and businesses can be better gear themselves to serving their customers in either of the shopping venues.

\section{LITERATURE REVIEW}

As Internet usage is increasing, so is online shopping, especially in those countries whose marketing infrastructures are well developed [14]. Consumers can shop at anytime and have access to products not available in their geographic region. Furthermore, they are now able to access the Internet, not only from their personal computers, but from advanced electronic devices such as PalmPilots and mobile phones [14]. Also, due to an increase in high-speed Internet access connections, lower connection costs, and increasing consumer competence, e-commerce activity will continue to grow as the availability and ease with which the Internet provides consumers the ability to handle needed tasks increasingly develops. 
In conjunction with the increases in Internet capabilities, it is estimated that about $53 \%$ of Internet users in the United States have made an online purchase [10]. However, not all consumers are turning to the Internet for shopping. While the number of Internet users who have made a purchase at one time is more than half in the United States, this does not explain the disparity between the number of visits websites recorded and the number of actual purchases made online. One report shows that although a web site may receive millions of visitors, only about $3 \%$ of those visits result in a purchase online [4], and according to another study, about $65 \%$ of online shopping carts are abandoned before a purchase is completed [22]. An explanation of these occurrences is that the majority of consumers are going online to window-shop with plans to make their purchases in a more traditional, offline setting [9].

There have been several reasons examined in prior studies as to why some consumers have a preference for more traditional, offline means of purchasing products and services. One study found that consumers did not complete online purchases due to the intangibility of the purchase [6]. Some consumers have to satisfy certain sensory needs such as touch, taste, or smell, before making a purchase decision. Also, for some consumers, although visual images are provided with products or services, their sight needs may still not be satisfied. Another study found that as uncertainty in consumers about purchasing goods due to an inability to satisfy sensory needs increases, perceptions of risk with transactions increase. Even with precautionary research into a good or service and its vending company, every online transaction is perceived to have a basic level of risk by consumers due to issues of intangibility that cannot be avoided, such as hackers and whether the actual purchase choice is satisfactory based on information gleaned [12]. Consumers have a basic wonder about the security and accuracy of their online transactions. Especially for goods or services that consumers perceive to involve higher commitments, such as motor vehicles or computer cleaning services provided online, the intangibility of goods for some consumers can have a significant impact on their online purchasing decisions.

It has been reported that consumers have a low perception and trust of online merchants, making them unwilling to make purchases online. The results of a survey of 9700 online consumers showed that three out of five respondents did not trust web merchants [3]. Several studies also reported that consumers are concerned with their online security and privacy as online transactions still possess risk of information theft and fraud [2, 17]. This may be attributed to the fact that approximately $59 \%$ of online companies report at least one security breach each year [11]. In addition, it has been shown that approximately two-thirds of Americans are concerned with possible threats of Internet hackers and are not satisfied with current systems designed to protect them from such attacks [21]. A study of risk perceptions also indicates that consumers are concerned with undesirable outcomes and uncertainty of their purchases after purchasing a product online. Consumers, therefore, are less likely to make purchases online if they perceive a higher risk [7, 18].

Offline settings are not hindered by some of the online perceptions of risk. Offline settings are better able to provide some of the immediate satisfactions and sensory perceptions necessary to various consumers' purchasing decisions that lower associated risk perceptions with transactions, such as personal shopping assistance by personnel and immediate rights to a product or service. The availability of face-to-face interaction with business personnel to address consumer concerns is less prevalent and immediate in the online environment. Retailers are also finding that some consumers still prefer the offline ability to feel the immediate benefits of products rather than having to worry about a product or service while they wait for satisfaction via delivery by mail. This can increase the level of perceived risks with online transactions and affect the consumer's purchasing decision process [6]. The perception of risk associated with a company and their online presence can also be affected by previous encounters and also affect their decisions to complete purchases without sensory perceptions available in traditional brick-and-mortar stores. Consumers' previous experiences with online purchases, or lack thereof, can be a significant influence of levels of risk perception by consumers and their purchasing decisions [8]. Negative experiences increase levels of risk perception with online purchasing and hamper not only a businesses likelihood of retaining customers but can make it more difficult for other online businesses to gain initial customers [5].

In order to identify the differences between consumers who prefer online shopping and those who prefer offline shopping, this study examines how consumers perceive online shopping and which factors are perceived differently between consumers who prefer online shopping and consumers who prefer offline (physical store) shopping. The findings from this study will allow online businesses to be 
better informed of what draws consumers or prohibits them from coming to their websites. The better an online business understands the perceptions of these shoppers, the higher the chance that they can attract and retain customers.

\section{RESEARCH METHODOLOGY}

A direct survey was used to collect the data for this study. It was administered to random shoppers at local malls and to students at a southwestern United States university. The survey questions were compiled from previous study questions pertaining to the electronic commerce shopping behaviors [1, 13, $15,16,19,23]$. These questions were designed to gather data on the subjects' perceptions toward online shopping, especially their willingness to transact online. To validate the clarity of these questions, three professors and three researchers were asked to read through the survey questions. Revisions to the survey were made based on the feedback received.
The survey consists of 39 questions. Besides 19 questions on demographics, the remaining 20 questions were designed to examine subjects' perceptions on five factors:

1. the risk of online shopping,

2. the past experience with online shopping,

3. the benefits of online shopping,

4. the ease of online shopping, and

5. the level of uncertainty of online shopping.

The questions were rated on a 5-degree scale with 1 meaning "strongly disagree" and 5 meaning "strongly agree." One hundred and seven (107) individuals provided responses to the survey. However, eight of the responses were not completed, and thus were excluded from the result. Details on the subjects' demographics are provided in Table 1 below.

Table 1. Subjects' Demographics

\begin{tabular}{|c|c|c|c|c|}
\hline \multicolumn{5}{|l|}{ Age (in years) } \\
\hline Under 18: $0(0 \%)$ & 18-24: $66(66.67 \%)$ & 25-34: $25(25.25 \%)$ & 34-44: $6(6.06 \%)$ & 45 up: $2(2.02 \%)$ \\
\hline \multicolumn{5}{|l|}{ Gender } \\
\hline Male: $54(54.55 \%)$ & & Female: $45(45.45 \%)$ & & \\
\hline \multicolumn{5}{|c|}{ Highest Education } \\
\hline Less than GED & High School/GED & Bachelors & Masters up & Not answer \\
\hline $3(3.03 \%)$ & $33(33.33 \%)$ & $48(48.49 \%)$ & $5(5.05 \%)$ & $3(3.03 \%)$ \\
\hline
\end{tabular}

\begin{tabular}{lll}
\hline Student Status & & \\
Not student: $26(26.3 \%)$ & Undergraduate: $62(62.6 \%) \quad$ Graduate: $8(8.1 \%) \quad$ Not answer: $3(3.0 \%)$
\end{tabular}

\begin{tabular}{lllll}
\hline $\begin{array}{l}\text { Employment Status } \\
\text { Yes: } 79(79.80 \%)\end{array}$ & No: $19(19.19 \%)$ & Not answer: $1(1.01 \%)$ \\
\hline $\begin{array}{llll}\text { Income } \\
\text { Less than } \$ 20,000\end{array}$ & $\$ 20,000-40,000$ & $\$ 40,000-60,000$ & Greater than $\$ 60,000$ & Not answer \\
\hline $54(54.55 \%)$ & $14(14.14 \%)$ & $17(17.17 \%)$ & $6(6.06 \%)$ & $8(8.08 \%)$
\end{tabular}

\begin{tabular}{lllll}
\hline $\begin{array}{l}\text { Own Credit Card } \\
\text { Yes: } 91(91.92 \%)\end{array}$ & No: $8(8.08 \%)$ & & \\
\hline $\begin{array}{l}\text { Credit Card Type } \\
\text { Visa }\end{array}$ & MasterCard & American Express & Discover & Not answer \\
\hline $60(60.60 \%)$ & $26(26.26 \%)$ & $6(6.06 \%)$ & $3(3.03 \%)$ & $4(4.04 \%)$ \\
\hline
\end{tabular}

Internet Access

Yes: 94 (94.95\%)

No: $5(5.05 \%)$

Perform Online Transactions

Yes: 88 (88.89\%)
No: $10(10.10 \%)$
Not answer: 1(1.01\%) 


\section{ANALYSIS AND DISCUSSION}

To determine if there were significant differences on the factors between the groups of subjects who prefer shopping online (online group) and those subjects who prefer shopping from a physical store (offline group), t-tests on the means were conducted. The responses from subjects were divided into two groups based on their responses to the survey item Q21 -
"Overall, I prefer to shop online than in the physical store." The two groups were the online group, those who responded with a 4 or a 5 , and the offline group, those who responded with a 1 or a 2 . The subjects who were uncertain on this issue, those who responded with a 3 , were excluded from the t-tests. Table 2 below shows the factors exhibiting a significant difference between the two groups at a pvalue $<0.01$ and $<0.05$.

Table 2. Consumer Perceptions

\begin{tabular}{|l|c|c|l|}
\hline Factors & Mean: Online Group & Mean: Offline Group & \multicolumn{1}{|c|}{ p-value } \\
\hline Perceived Risk with Online Shopping & 2.53 & 3.38 & $0.0043^{* *}$ \\
\hline Past Experience with Online Shopping & 3.74 & 3.28 & $0.0272^{*}$ \\
\hline Perceived Benefits of Online Shopping & 3.89 & 3.14 & $0.0022^{* *}$ \\
\hline Perceived Ease of Online Shopping & 3.98 & 3.08 & $0.0001^{* *}$ \\
\hline Perceived Uncertainty of Online Shopping & 2.95 & 3.42 & $0.0500^{*}$ \\
\hline
\end{tabular}

$* *$ indicate $\mathrm{p}$-value $<0.01$

$*$ indicate $\mathrm{p}$-value $<0.05$

The results of the t-tests revealed a significant difference between the two groups on five factors: (1) perceived risk with online shopping, (2) past experience with online shopping, (3) perceived benefits of online shopping, (4) perceived ease of online shopping, and (5) perceived uncertainty of online shopping.

Three factors (past experience, perceived benefits, and perceived ease of online shopping) were rated higher by the online group. These results indicate that consumers who had positive experiences with online shopping, perceived more benefits on online shopping, and those that perceived that online shopping to be easier are likely to shop online. In contrast, two factors (perceived risk and perceived uncertainty) were rated lower by the online group. Such results indicate that those consumers who perceived a higher risk and higher uncertainty with online shopping prefer shopping at a physical store. These findings suggest that in order to attract more customers, online businesses should make their potential customers aware of the security techniques implemented on their websites. It is also important to make customers feel more certain when shopping online (e.g., guarantee delivery date, easy return policy, etc.).

\section{CONCLUSION}

This study has provided an empirical glimpse into the minds of consumers as to what factors are perceived differently by consumers who prefer online shopping and those who prefer offline shopping. The results revealed that five factors were perceived differently between these two groups of consumers. These factors were: (1) perceived risk with online shopping, (2) past experience with online shopping, (3) perceived benefits of online shopping, (4) perceived ease of online shopping, and (5) perceived uncertainty of online shopping. Determining such factors may provide online businesses with a base level awareness of online consumers' perceptions and of what factors into preferences for online or offline shopping avenues. This awareness could provide insights into what needs to be done to attract and retain more online customers. Based on these findings, online businesses could make several adjustments and enhancements to their online presence to conform to the perceptions of their potential customers. The businesses can capitalize on these findings in an effort to boost online perceptions. Being aware of what perceptions drive consumers to pick and prefer one avenue of shopping to another allows businesses to better cater to consumers, thus helping them attract and retain customers.

While this survey helped readers to gain insight on the perception of consumers, these initial findings still warrant further investigation. To achieve a better understanding of these factors, future research should include a larger sample size and more variety in terms of subjects' sources. The study also leads to several avenues for future research. For instance, the study results suggest that customers who perceive more benefits prefer online shopping. Future research may further investigate what benefits consumers find with online shopping and how this can be improved. This information may help offline stores who are venturing into an online setting to better understand 
what influences consumer preferences and how they may provide maximum customer satisfaction with each transaction. Understanding perceptions of risk that may be associated with different products and services may enable online businesses to create more positive experiences.

\section{REFERENCES}

1. Alomaim, N., Tunca, M. Z., \& Zairi, M. (2003). Customer satisfaction @ virtual organizations. Management Decision, 41(7), 666-670,

2. Attran, M., \& VanLaar, I. (1999). Privacy and security over the Internet: how to secure your personal information and company data. Information Management \& Computer Security, 7(5), 241.

3. Belanger, F., Hiller, J.S., \& Smith, W.J. (2002). Trustworthiness in Electronic Commerce: the role of privacy, security, and site attributes. Journal of Strategic Information Systems, 11, 245-270.

4. Betts, M. (2001). Turning browsers into buyers. MIT Sloan Management Review, 42(2), 8-9.

5. Boyer, K. K., \& Hult, G. T. M. (2005). Customer behavior in an online ordering application: A decision scoring model. Decision Sciences, 36(4), 569-598.

6. Cho, J. (2004). Likelihood to abort an online transaction: Influences from cognitive evaluations, attitudes, and behavioral variables. Information and Management, 41, 827-838.

7. Choi, J. \& Lee, K. (2003). Risk perception and eshopping: a cross-cultural study. Journal of Fashion Marketing and Management, 7(1), 4964.

8. Dillon, T. D., \& Reif, H. L. (2004). Factors influencing consumer's e-commerce commodity purchases. Information Technology, Learning, and Performance, 22(2), 1-12.

9. Forsythe, S. M., \& Shi, B. (2003). Consumer patronage and risk perceptions in Internet shopping. Journal of Business Research, 56(11), 867-875.

10. George, J. F. (2004). The theory of planned behavior and Internet purchasing. Internet Research, 14(3), 198-212.

11. Hopwood, W. S., Sinason, D., \& Tucker, R. R. (2000). Security in a Web-based environment. Managerial Finance, 26(11), 42-55.

12. Huang, W., Schrank, H., \& Dubinsky, A. J. (2004). Effect of brand name on consumer's risk perceptions of online shopping. Journal of Consumer Behavior, 4(1), 40-50.

13. Joines, J. L., Scherer, C. W., \& Scheufele, D. A. (2003). Exploring motivations for consumer Web use and their implications for e-commerce. Journal of Consumer Marketing, 20 (2), 90-108.

14. Kau, A. K., Tang, Y. E., \& Ghose, S. (2003). Typology of online consumers. Journal of Consumer Marketing, 20(2), 139-156.

15. Koivumäki, T. (2001). Customer Satisfaction and Purchasing Behavior in a Web-based Shopping Environment. Electronic Markets, 11(3), 186-192.

16. Koyuncu, C. \& Lien, D. (2003). E-commerce and consumer's purchasing behavior. Applied Economics, 35(6), 721-725.

17. Kruck, S. E., Gottovi, D., Moghadami, F., Broom, R., \& Forcht, K. A. (2002). Protecting personal privacy on the Internet. Information Management \& Computer Security, 10(2/3), 7784.

18. Lim, N. (2003). Consumer's perceived risk: sources versus consequences. Electronic Commerce Research \& Applications, 2(3), 216228.

19. Lin, C. C. (2003). A critical appraisal of customer satisfaction and e-commerce. Managerial Auditing Journal, 18 (3), 202-212.

20. Mahmood, M. A., Kohli, R., \& Devaraj, S. (2004). Introduction to the Special Issue: Measuring the Business Value of Information Technology in e-Business Environments. International Journal of Electronic Commerce, 9(1), 5-8.

21. McCrohan, K. F. (2003). Facing the threats to electronic commerce. Journal of Business \& Industrial Marketing, 18(2), 133-145.

22. O'Neill, B. (2001). Online shopping: Consumer Protection and Regulation. Consumer Interests Annual, (47), 1-3.

23. Posnock, S. (2004). Customer satisfaction up online. American Demographics, 26(3), 16-16.

24. Rodgers, S. \& Harris, M. A. (2003). Gender and e-commerce: An exploratory study. Journal of Advertising Research, 43(3), 322-329.

25. Shim, S., Eastlick, M. E., Lotz, S. L., \& Warrington, P. (2001). An online prepurchase intentions model: The role of intention to search. Journal of Retailing, 77(3), 397-216.

26. Udo, G. J. (2001). Privacy and security concerns as major barriers for e-commerce: A survey study. Information Management \& Computer Security, 9(4), 165-174. 